ISSN 2179-345X

Licenciado sob uma Licença Creative Commons

\title{
O princípio da função social do contrato nas relações empresariais
}

\author{
The contract's social function principle \\ in the enterprises relationship
}

\begin{abstract}
Leonidas Cabral Albuquerque
Advogado, mestrando em Direito pela Pontifícia Universidade Católica do Rio Grande do Sul (PUCRS), Porto Alegre, RS - Brasil, e-mail: leonidas@leonidas.adv.br
\end{abstract}

\section{Resumo}

Em uma perspectiva histórico-evolutiva das sociedades e da atividade econômica, o contrato é o agente civilizador por excelência, substituindo a apropriação violenta de bens pelo acordo de vontades, o que vem a ser a expressão primeira da função social do contrato. Este, a partir da Revolução Francesa, passa a ser importante instrumento progressista fundado nos postulados da liberdade e da igualdade. A propriedade adquire função social para além da representação de riqueza e poder individuais, passando a expressar-se como bem de produção capaz de contribuir ao bem-estar comum. Paralelamente, a função social do contrato está na criação e no cumprimento das relações e dos negócios jurídicos, aproximando produtores e pessoas ao mesmo tempo em que se afirma como expressão da individualidade humana. A força obrigatória do contrato passa a ser relativizada a partir 
da Primeira Guerra Mundial, em face dos fenômenos que ensejam a onerosidade excessiva de um dos sujeitos, ou alteram sobremaneira o equilíbrio econômico ou a base do negócio. A possibilidade de revisão do contrato impõe-se no Direito ocidental, primeiramente na Europa - exposta diretamente aos efeitos da Primeira Guerra -, e no Brasil, onde a resistência da doutrina tradicional é rompida pela jurisprudência. A Constituição de $1988-$ que tem dentre os objetivos a solidariedade social e estabelece uma ordem econômica que projeta a harmonia da livre-iniciativa com os interesses metaindividuais - é fonte do princípio da socialidade incorporado no Código Civil de 2002, conferindo nova dimensão ao princípio da função social do contrato.

Palavras-chave: Direito Civil. Contrato. Função social.

\begin{abstract}
In a historical-evolutionary perspective of societies and the economic activity, the contract is the civilizing agent by excellence, replacing violent appropriation of goods for the agreement of wills, which happens to be the first expression of the social function of the contract. The contract, since the French revolution becomes an important progressive instrument based on the principles of freedom and equality. The property acquires social function beyond the individual representation of wealth and power, starting to express itself as a production good capable of contributing to the common welfare. At the same time, the social function of the contract is in the creation and performance of legal relations and business, bringing producers and people while that states as an expression of human individuality. The binding force of contract shall be relativized since the First World War concerning phenomena that either lead to the excessive cost for one of the contracting parties, or change excessively the economic balance or the contract base. The possibility of a contract review imposes in Western Law, first in Europe-exposed directly to the effects of World War I, and in Brazil, where the resistance of traditional doctrine is broken by the jurisprudence. The Constitution of 1988 - which has among its objectives the social solidarity and establishes an economic order that casts the harmony of free enterprise with metaindividual interests - is the source of the "sociality principle" incorporated by the 2002 Civil Code, and gives new dimension to the principle of the social function of the contract
\end{abstract} Keywords: Civil law. Contract. Social function.

Rev. Direito Econ. Socioambiental, Curitiba, v. 3, n. 2, p. 335-353, jul./dez. 2012 


\section{Introdução}

A mercancia é desenvolvida pelos produtores, mercadores e artesãos, em atividades individuais ou com parca organização, conforme as condições de vida das primeiras civilizações. Com o incremento da organização dessas atividades, esses profissionais passam a ser integrantes de corporações fechadas, de artes ou de ofícios, com regramentos e jurisdição próprios.

Com a Revolução Francesa emancipa-se a burguesia, elevando-se à condição de classe dominante. As corporações de ofício são abolidas e a concepção da atividade econômica passa a ser centrada na prática de atos de comércio, conforme o sistema francês, inaugurado com o Code de Commerce de 1808, o Código Mercantil Napoleônico. Passam a ser comerciantes todos os que praticarem atos de comércio, exercendo profissionalmente essa atividade.

O primado da liberdade na Revolução Francesa alcança todas as áreas e relações: na economia, liberta a burguesia para o exercício da produção e comercialização de bens e serviços; na sociedade, liberta os servos dos grilhões do senhor feudal, passando a produzir em terra própria (reforma agrária) ou ao desempenho de atividade assalariada, no campo ou nas cidades. Nas relações jurídicas comuns ou comerciais, a liberdade e a igualdade convertem a livre manifestação de vontade em contrato, na formalização de negócios jurídicos que, dentro dos parâmetros de licitude, se rege por si só.

No que se refere à propriedade - que a Revolução recém distribuíra entre os servos ao extinguir os feudos -, percebe-se um fenômeno diverso da fórmula individualista dos contratos. A Igreja Católica, baseada no pensamento tomista, passa a identificar a propriedade como bem de produção, e não como valor inserido na riqueza de alguém; um bem que contém em si uma função social, uma capacidade de contribuir para o bem-estar comum, de modo a conduzir o seu uso às melhores formas de justiça social (HIRONAKA, 1988).

Assim, a função social da propriedade representa sua finalidade útil, produtiva, para suprimento de necessidades que não se limitam às do 
proprietário, mas que são de todos. Depreende-se, então, que os bens de produção passam a ser juridicamente associados à função produtiva - o que identifica a doutrina social da Igreja Católica.

Para o desempenho da atividade econômica, o homem necessita: a) de bens de produção, para produzir bens de consumo e vendê-los; b) de bens produzidos para serem vendidos; c) de instrumentos laborais para prestar serviços e ser remunerado; e d) relações comerciais com seus clientes ou com a praça. Em todos esses elementos há diversas formas em que a propriedade se apresenta e troca de mãos, assim como inúmeros são os contratos a serem desenvolvidos para resultar em lucro, que é a finalidade de quem exerce a atividade econômica.

Os contratos realizados entre as empresas compõem o objeto do presente estudo, cujo objetivo é averiguar a incidência e atuação do princípio da função social do contrato. Para tanto, verificar-se-á no que consiste o princípio da função social do contrato, alguns contratos empresariais e seus efeitos, a legislação brasileira, a doutrina e alguns casos que ilustram a jurisprudência.

\section{O princípio da função social do contrato: autonomia da vontade e função social}

Do ponto de vista da evolução humana e das sociedades, os povos e as civilizações mais antigas já se utilizavam do contrato e praticavam o comércio - os fenícios, o antigo Egito, a Grécia, Roma. A sociedade romana "vencera, mesmo antes do período clássico, a concepção da apropriação violenta de utilidades" (PEREIRA, 1990, p. 9). Ao substituir, paulatinamente, a apropriação violenta de bens pelo ajuste de vontades, visando ao suprimento recíproco de necessidades, o contrato apresenta sua função civilizadora como primeira função social.

$\mathrm{Na}$ esteira da liberdade e da igualdade, o contrato é tido como produto da livre manifestação de vontades por, pelo menos, duas pessoas. Na lição de Santos Carvalho ([1947?]): contrato é o ato jurídico que 
traduza o acordo de vontade de duas ou mais pessoas, para o fim de criar, resguardar, modificar ou extinguir uma relação jurídica. Essa concepção de autonomia da vontade alcança o século XX sendo incorporada ao Código Civil de 1916 (art. 1.079). O mundo moderno passa a ser compreendido como o mundo do contrato, cuja relevância econômica torna inimaginável a vida e a atividade do homem.

Além do papel econômico, o contrato desempenha função de harmonizar a vida social, aproximando as pessoas e, enquanto cumpridas as suas cláusulas, atendendo aos respectivos interesses. Assim, o contrato possui também uma função social vislumbrada, inicialmente, na "afirmação de maior individualidade humana", conforme afirma Caio Mário da Silva Pereira (1990, p. 16):

aquele que contrata projeta na avença algo de sua personalidade. O contratante tem consciência do seu direito e do direito como concepção abstrata. Por isso, realiza dentro das suas relações privadas um pouco da ordem jurídica total. Como fonte criadora de direito, o contrato assemelha-se à lei, embora de âmbito mais restrito. Os que contratam assumem, por momento, toda a força jurígena social. Percebendo o poder obrigante do contrato, o contraente sente em si o impulso gerador da norma de comportamento social, e efetiva esse impulso.

A obrigatoriedade do contrato decorre da sua função social. E a força obrigatória deste é assim explicada: "o contrato obriga porque as partes livremente o aceitam" (PEREIRA, 1990, p. 18). Ou seja, a função social do contrato, ao mesmo tempo, decorre e consagra a livre manifestação da vontade.

O primado da livre manifestação de vontade e da força obrigatória do contrato começa a ruir a partir da Primeira Guerra Mundial, que abala profundamente todos os povos da Europa. Contratos de longo prazo, cujas bases são estabelecidas antes da Guerra e em uma perspectiva de estabilidade social e econômica, tornam-se inexequíveis, ou executáveis com enormes sacrifícios, ou mesmo ocasionando a quebra dos obrigados. A esse respeito, anotam Fida e Cardoso (1987): 
os princípios da Revisão dos Contratos, recalcitrados nos ditames do direito Romano, veio à tona após a deflagração da Primeira Guerra Mundial (1914/18), alterando e provocando mudanças substanciais na ordem econômica e social em toda a estrutura política da velha Europa. Foi justamente nessa época que o nosso Código Civil foi aprovado.

Outros códigos que advieram após a catástrofe bélica deram destaque à Revisão dos Contratos, tendo por escopo a necessidade de um melhor equilíbrio sócio-econômico. Dentre outros, podemos citar os códigos civis: italiano, polonês e o português, sendo que no direito saxônico aparece com o nome de frustration.

A cláusula rebus sic standibus, no Direito brasileiro, foi alvo de resistência por parte da doutrina fundada na força vinculativa dos contratos. Santos Carvalho ([1947?]), por exemplo, afirma a repulsa da doutrina nacional à tentativa de alguns juristas fazerem reviver a cláusula rebus sic stantibus, como cláusula resolutória tácita, pois "equivaleria a destruir o princípio inconteste da força vinculativa do contrato, que vale como lei entre as partes".

Todavia, o Supremo Tribunal Federal passa a admitir a teoria da imprevisão, que é tida como implícita no Código Civil. Tal teoria é utilizada como fundamento para admitir a revisão judicial de obrigações em virtude de alteração radical do estado de fato, como na prestação de alimentos, então regrada no art. 401 do Código Civil de $1916^{1}$.

Nos termos do art. 1.246 daquele Código, que dispunha sobre o contrato de empreitada, havia a atribuição de todo o risco do empreendimento ao empreiteiro, mas de forma absoluta:

Art. 1.246 - O arquiteto, ou construtor, que, por empreitada, se incumbir de executar uma obra segundo plano aceito por quem a encomenda, não terá direito a exigir acréscimo no preço, ainda que o dos salários, ou o do material, encareça, nem ainda que se altere ou aumente, em

1 Recurso Extraordinário n. 18.518, relator o Ministro Nelson Hungria, Primeira Turma do STF, j. 19.11.1952, DJU de 10.09.1953. Ementa: "pensão alimentícia clausulada por ocasião do desquite: possibilidade de revisão. O art. 401 do Código Civil é uma aplicação particular da cláusula rebus sic stantibus". 
relação à planta, a obra ajustada, salvo se se aumentou, ou alterou, por instruções escritas do outro contratante e exibidas pelo empreiteiro.

Em uma realidade econômica instável, inflacionária, em que o custo de insumos e mão de obra não dependia da vontade do empreiteiro, o texto legal poderia tornar-se absolutamente adverso diante de períodos de crise. Nesse cenário o índice de inflação poderia disparar abruptamente, o valor da moeda nacional poderia sofrer desvalorização diante de súbita alta do dólar americano e haver escassez de materiais fundamentais para o desenvolvimento da obra, o que acarretaria alta inesperada dos respectivos preços. Ainda assim, a aplicação da cláusula rebus sic stantibus era admitida pelo STF apenas excepcionalmente, quando o imprevisto a ser suportado pelo empreiteiro atingia o seu patrimônio, não apenas a sua expectativa de lucro com o negócio ${ }^{2}$.

A finalidade da revisão por tal fundamento é a retomada do equilíbrio em que se encontravam os contratantes no momento da contratação, a fim de que seja alcançada a função social do contrato - agora já albergando, em seu significado, a produção do resultado esperado com o seu adimplemento.

\section{O novo paradigma da função social no Código Civil de 2002}

O Código Civil de 2002 - cujo projeto foi debatido desde 1975 incorporou o princípio da socialidade, cuja fonte é a Constituição Federal (art. $3^{\circ}$, inc. I) "e sua aplicação ao Código Civil é fruto do reconhecimento da mudança dos valores da sociedade que forma e transforma o direito" (REMÉDIO Jr., 2012, p. 308).

\footnotetext{
2 Recurso Extraordinário n. 85.714, relator o Ministro Soares Muñoz, Primeira Turma, j. 19.06.1979, DJU de 03.07.1979. Trecho da ementa: "a aplicação da cláusula rebus sic stantibus não importa na negativa de vigência do art. 1.246 do Código Civil, se ocorre aumento imprevisível no surto inflacionário, depois de celebrado o contrato e no prazo da execução das obras".
} 
A função social do contrato encontra previsão no art. 421 do novo Código Civil. Imbuído de socialidade, o princípio é normatizado para impor limites à liberdade de contratar: "Art. 421. A liberdade de contratar será exercida em razão e nos limites da função social do contrato".

A partir dessa norma, o Conselho da Justiça Federal (2002), em estudos concludentes da I Jornada de Direito Civil (BRASIL, 2002) acerca do novo Código Civil, emitiu os seguintes enunciados para compreensão da função social do contrato:

21 - Art. 421: a função social do contrato, prevista no art. 421 do novo Código Civil, constitui cláusula geral a impor a revisão do princípio da relatividade dos efeitos do contrato em relação a terceiros, implicando a tutela externa do crédito.

22 - Art. 421: a função social do contrato, prevista no art. 421 do novo Código Civil, constitui cláusula geral que reforça o princípio de conservação do contrato, assegurando trocas úteis e justas.

23 - Art. 421: a função social do contrato, prevista no art. 421 do novo Código Civil, não elimina o princípio da autonomia contratual, mas atenua ou reduz o alcance desse princípio quando presentes interesses metaindividuais ou interesse individual relativo à dignidade da pessoa humana.

Coelho (2007, p. 36) mira o parágrafo único do artigo 2.035 do novo Código Civil para afirmar a solidez do princípio da função social e da norma do art. 421 do mesmo Código, "no sentido da invalidade dos contratos que não a cumprem". E fundamenta: "tanto assim que considera o Código, numa regra de caráter transitório, que o contrato sem função social é nulo por contrariar norma de ordem pública".

Eis o texto do artigo 2.035, parágrafo único:

Art. 2.035. A validade dos negócios e demais atos jurídicos, constituídos antes da entrada em vigor deste Código, obedece ao disposto nas leis anteriores, referidas no art. 2.045, mas os seus efeitos, produzidos após a vigência deste Código, aos preceitos dele se subordinam, salvo se houver sido prevista pelas partes determinada forma de execução.

Rev. Direito Econ. Socioambiental, Curitiba, v. 3, n. 2, p. 335-353, jul./dez. 2012 
Parágrafo único. Nenhuma convenção prevalecerá se contrariar preceitos de ordem pública, tais como os estabelecidos por este Código para assegurar a função social da propriedade e dos contratos (BRASIL, 2002).

Tal regulação equipara a norma do art. 421 do novo Código Civil a preceito de ordem pública. A função social do contrato abandona o referencial do interesse puramente privado, deixando de pautar-se exclusivamente pelos paradigmas da função civilizatória e da afirmação da autonomia da vontade.

Ao mesmo tempo, a lesão e a onerosidade excessiva ganham autonomia normativa no novo Código Civil, respectivamente nos artigos 157 e 478 a 480 . Antes da positivação, as pretensões de revisão judicial do contrato por ocorrência de lesão ou de onerosidade excessiva, eram fundamentadas no princípio da função social do contrato, no da comutatividade contratual, na implícita cláusula rebus sic stantibus, etc.

Essa alteração possui consequências práticas, na medida em que a lesão e a onerosidade excessiva passam a ter seus próprios fundamentos legais ${ }^{3}$ e prazos específicos de exercício: a) a lesão decai em quatro anos, contado do dia em que se realizou o negócio jurídico (art. 178, inc. II); b) a onerosidade excessiva deve ser reclamada de imediato, ou seja, ainda durante a execução do contrato, haja vista que é causa de resolução (art. 478), ou de reequilíbrio da obrigação (nas condições do art. 479), podendo-se também prevenir a ocorrência da excessiva onerosidade (art. 480).

Ultrapassados os momentos ideais do exercício das pretensões pertinentes à onerosidade excessiva, há outras duas hipóteses de solução judicial, cujo prazo prescricional é de três anos (art. 206, $§ 3^{\circ}$ ): a) o onerado poderá pleitear ressarcimento pelo enriquecimento indevido do credor da obrigação, contado o prazo do momento em que o enriquecimento se

3 A lesão e a onerosidade excessiva permanecem corolários da função social do contrato, o que está sedimentado no enunciado 22 da I Jornada de Direito Civil do CNJ. Contudo, parece lógico que, a partir da vigência do novo Código Civil, as pretensões decorrentes da lesão e da onerosidade excessiva estão sujeitas às normas respectivas, que condicionam o direito e seu exercício como fonte primária no sistema jurídico brasileiro. 
consolida; ou b) a reparação de danos que tenha sofrido pela oneração excessiva, contado o prazo do momento em que o dano se materializa.

Como cláusula geral, a função social do contrato sofre a mutação da contemporaneidade, com influência direta da Constituição de 1988, cujos direitos e garantias fundamentais individuais e sociais estão albergados nos arts. $5^{\circ}, 6^{\circ}$ e $7^{\circ}$, e que, na Ordem Econômica, consagra diversos princípios vetores para o atingimento da "existência digna, conforme os ditames da justiça social” (artigo 170). O novo Código Civil confere ao princípio da função social do contrato a incumbência de limitar a liberdade de contratar. A socialidade passa a influir mais diretamente na função social do contrato, que se abastece e fortalece com os interesses do consumidor, do meio ambiente, do pleno emprego e da superação das desigualdades regionais.

Do disposto no art. 421 do novo Código Civil, à luz do artigo 170 da Constituição Federal, verifica-se que o contrato não pode mais ser analisado metafisicamente, em si mesmo, isolando o negócio e a relação jurídica com seus sujeitos e partícipes. Ele deve ser estudado como um fenômeno que repercute socialmente, fora do negócio e além dos sujeitos que lhe dão origem, passando, pois, a ser limitado pela sua função social. O direito posto revitaliza o princípio da relatividade dos contratos, segundo o qual o contrato não pode gerar obrigações ou ônus para terceiros, alheios à relação contratual. Por força do princípio da relatividade e da boa-fé objetiva, depreende-se que terceiros não podem ser, por qualquer modo, afetados negativamente pelo contrato. E nessa concepção de "terceiros" encontram-se os titulares de interesses individuais, públicos, coletivos ou difusos.

Assim, a função social do contrato tem outro referencial, conforme corretamente identificado nos Enunciados n. 21 e 23 do Conselho da Justiça Federal. O princípio da relatividade do contrato em relação a terceiros passa a conferir a coloração predominante da função social do contrato, determinando-lhe a mitigação do princípio da autonomia da vontade, quando presentes interesses metaindividuais, públicos, coletivos, difusos ou interesse individual relativo à dignidade da pessoa humana. 


\section{Contratos entre empresas e o princípio da função social: função social dos contratos e a empresa como corpo social}

As sociedades comerciais, ao longo da história, adquiriram diversas formas, conforme a distribuição da responsabilidade pelos negócios sociais entre os sócios. Toma-se, neste estudo, a forma societária econômica por natureza - a sociedade anônima -, de estrutura mais complexa, contando com acionistas, Conselho de Administração, Conselho Diretor (ou Diretoria Executiva), Conselho Fiscal, entre outros, como modelo para identificar o universo da empresa.

Antes da edição do novo Código Civil, a empresa estava sujeita ao regramento do Código Comercial, que regulava a atividade dos comerciantes (individuais ou empresas), que praticavam, profissionalmente, atos de comércio. Assim, no caso das sociedades empresárias, a função social dos contratos empresariais não está restrita à própria relação jurídica contratual, tal como os contratos individuais na órbita do Direito Civil, mas estende-se ao âmbito interno da organização, aos órgãos colegiados: Conselho de Administração, Conselho Diretor, Conselho Fiscal, Assembleia Geral e também ao âmbito externo, entendidos tão somente aqueles que diretamente contribuem para o empreendimento - investidores, acionistas, trabalhadores.

Os negócios da empresa devem estar em conformidade com as finalidades estatutárias, correspondendo às expectativas de lucros dos acionistas, dos investidores e também dos trabalhadores que passam a dele participar ${ }^{4}$. Esse conteúdo da função social resulta bastante ampliado a partir do novo Código Civil.

\footnotetext{
4 Veja-se, a respeito, o art. 116, parágrafo único, da Lei n. 6.404/76; sobre participação dos trabalhadores nos lucros das empresas, v. Lei n. 10.101/2000.
} 


\section{Função social dos contratos entre empresas, após a vigência do novo Código Civil}

Com a unificação das obrigações civis e comerciais e a regulação da empresa no novo Código Civil, os contratos empresariais estão sujeitos ao mesmo princípio da função social do artigo 421, atuando como razão [motivo e/ou fundamento] e como limite, que impacta diretamente os contratos entre as empresas (inclusive entre elas e o Poder Público).

Conforme Silva (2006, p. 135), a função social do contrato "é uma forma de concretização do objetivo constitucional da solidariedade social". Nessa mesma esteira, Coelho (2007, p. 38) não vislumbra a função social no contrato que atinja interesses metaindividuais, como, por exemplo, interesses coletivos ou difusos sobre os quais os contratantes não possuem disponibilidade. Afirma o autor:

o dano ambiental, a publicidade enganosa e a sutil forma de impor degradação ao imóvel tombado são efeitos dos contratos que violam o meio ambiente, os direitos dos consumidores e o patrimônio histórico. Desatende-se, nesses casos, à função social exigida nos negócios contratuais.

$[\ldots]$

A consequência para a inobservância da cláusula geral da função social do contrato é a nulidade do negócio jurídico e a responsabilidade dos contratantes pela indenização dos prejuízos provocados.

Assim, a nova concepção da função social dos contratos aplicada aos negócios jurídicos entre empresas pressupõe o não atingimento dos interesses de terceiros, interesses metaindividuais. Adquire o caráter de ilicitude a oneração ou o prejuízo dos interesses dos consumidores, do meio ambiente e do patrimônio histórico e cultural - ficando nos exemplos de Coelho (2007).

A partir dessa nova concepção da função social do contrato, adquire cada vez mais importância o tratamento, por exemplo, das externalidades - efeitos colaterais da produção de bens ou serviços sobre outras 
pessoas que não estão diretamente envolvidas com a atividade - decorrentes de negócios jurídicos entre empresas, e entre elas e o Poder Público.

As externalidades referem-se ao impacto de uma decisão sobre aqueles que não participaram dessa decisão ${ }^{5}$. Esses impactos podem ser: negativos - poluição causada pela indústria; ou positivos - o incremento da atividade econômica na região.

Do ponto de vista ambiental, as externalidades podem ser geralmente mensuradas mediante análise de impacto ou de risco ambiental. Essa análise não é exigida legalmente para todas as atividades econômicas, mas é possível para a gestão pública comprometida com a sustentabilidade ${ }^{6}$ desenvolver políticas de estímulo ao desenvolvimento regional que evitem a instalação de atividades econômicas acarretadoras de externalidades negativas, ao mesmo tempo em que estimulem as atividades que possam gerar externalidades positivas.

Esse conceito é utilizado na área das Ciências Contábeis, que toma "a externalidade como o fato inquestionável de que qualquer atividade afeta, de modo favorável ou desfavorável, outras atividades ao longo do processo produtivo" (FERREIRA, 1998 apud LIMA; VIEGAS, 2002, p. 47). Contabilmente, já há preocupação com a transparência de dados imateriais das empresas - balanço social, demonstração de valor adicionado -, sendo o fator ambiental considerado como item mensurável e demonstrável.

A falta de sustentabilidade ambiental pode limitar o crescimento econômico em geral, mas o custo da externalidade não é levado em conta

\footnotetext{
5 LICENCIAMENTO AMBIENTAL em Mato Grosso do Sul: informações sobre meio ambiente, licenciamento ambiental, tecnologias, gestão e controle ambiental. Disponível em: <http://www.licenciamentoambiental.eng.br/conceito-de-externalidades/\#ixzz1u90uA1j1>. Acesso em: 6 maio 2012.

6 De acordo com Freitas (2011), sustentabilidade é “o princípio constitucional que determina, independentemente de regulamentação legal, com eficácia direta e imediata, a responsabilidade do Estado e da sociedade pela concretização solidária do desenvolvimento material e imaterial, socialmente inclusivo, durável e equânime, ambientalmente limpo, inovador, ético e eficiente, no intuito de assegurar, preferencialmente de modo preventivo e precavido, no presente e no futuro, o direito ao bem-estar físico, psíquico e espiritual, em consonância homeostática com o bem de todos". FREITAS, J. Sustentabilidade: direito ao futuro. Belo Horizonte: Fórum, 2011.
} 
pelo produtor (WEYDMANN, 2005). Essa é uma constatação também noticiada pelo Instituto Brasileiro de Altos Estudos de Direito Público:

a diminuição de restrições ambientais, característica do neoliberalismo dos anos 1980 e 1990, e a falta de internalização das externalidades (ou seja, a não valoração e não contabilização dos impactos socioambientais negativos nos preços de bens e serviços) reforçam a equação básica da maximização do lucro e rebaixamento dos custos de produção. Do mesmo modo, a transformação de bens comuns em mercadorias - por exemplo, a compra e venda de espaço na atmosfera por meio do mercado de emissões de carbono - é vista por alguns desses movimentos não como a forma de gestão de um patrimônio natural, mas como meio de criação de novos mercados e mercadorias, passíveis de especulação e de apropriação privada, e assim capazes de servir à contínua acumulação capitalista (INSTITUTO..., 2012).

Para Lima e Viegas (2002, p. 49), uma das formas de neutralizar as externalidades ecológicas é "a internalização, ou seja, o reconhecimento de seus efeitos na apuração dos resultados da empresa", indicando que:

o melhor caminho é reduzir o impacto ecológico pelo lado do ajustamento da demanda, diminuindo o requerimento dos recursos sem substituí-los, considerando o tamanho e a capacidade de renovação do recurso, a reciclagem e a capacidade de redução do consumo do recurso.

Além da internalização, Lima e Viegas (2002, p. 49) indicam "outros mecanismos disponíveis, como o princípio do poluidor-pagador, o tratamento direto como custos ambientais e a tributação".

Tramita na Câmara Federal o Projeto de Lei n. 1.572/2011 Novo Código Comercial ${ }^{7}$, que absorve e sistematiza a função social do

7 Faz-se menção ao PL n. 1.572/2011, da Câmara dos Deputados, apenas para verificação do modo pelo qual a matéria da função social do contrato está prevista, sendo relevante do ponto de vista acadêmico. Todavia, trata-se de uma tentativa de retorno à legislação por microssistemas, aliás, metodologia abandonada com a edição do Código Civil de 2002, que unificou as obrigações civis e comerciais, além de dispor sobre a empresa - embora se reconheça que não o fez de forma 
contrato, calcada no princípio da relatividade em relação a terceiros, nos termos do previsto no parágrafo único do art. 316: "o contrato empresarial não cumpre a função social quando, embora atendendo aos interesses das partes, prejudica ou pode prejudicar gravemente interesse coletivo, difuso ou individual homogêneo".

As externalidades estão incorporadas no texto do projeto, dispondo que o juiz, diante de externalidades negativas pode decretar a nulidade do contrato, resultado esse inexistente diante de externalidades positivas ( $§ 2^{\circ}$, do art. 317 do PL n. 1.572/2011).

De fato, a efetiva internalização, pelas empresas contratantes, dos impactos econômicos das externalidades com a correspondente transparência da informação mediante a contabilização dos créditos e débitos ambientais, em contas específicas nas suas demonstrações contábeis, e com apuração de um resultado ambiental, tal como indicado e defendido por Lima e Viegas (2002), podem ser medidas que contribuam sobremaneira com o desenvolvimento de uma economia realmente sustentável, com pleno respeito à função social do contrato.

\section{Conclusão}

A partir da vigência do novo Código Civil, que concebeu, no artigo 421, a função social do contrato como um limite à liberdade de contratar, deixou-se de pautar pelos seculares paradigmas da função civilizatória e da afirmação da autonomia da vontade. Supera-se, inclusive, a concepção de reequilíbrio da economia contratual ou de evitar a lesão de um dos contratantes.

exauriente, eis que ressalva a legislação especial das sociedades por ações (Lei n. 6.404/76), por exemplo. Destaca-se a centralidade alcançada com o novo Código Civil, assim como a harmonização de institutos iguais ou semelhantes que eram regulados de forma distinta no Direito comum e no dos comerciantes. A codificação ainda possui importante papel a cumprir e a experiência atual merece ser aprofundada no âmbito do Direito privado. Acompanha-se, nesse sentido, ANDRADE, F. S. de. Da codificação: crônica de um conceito. Porto Alegre: Editora do Advogado, 1997. 
Releva-se o fundamento da socialidade e da boa-fé objetiva, com os contornos dos direitos e garantias fundamentais da Constituição de 1988.

Como cláusula geral, a função social do contrato sofreu a mutação da contemporaneidade, com influência direta da Constituição de 1988, cujos direitos e garantias fundamentais individuais e sociais estão albergados nos arts. $5^{\circ}, 6^{\circ}$ e $7^{\circ}$, e que, na Ordem Econômica, consagra diversos princípios vetores para o atingimento da "existência digna, conforme os ditames da justiça social” (art. 170). A socialidade influi mais diretamente na função social do contrato, que se abastece e se fortalece com os interesses do consumidor, do meio ambiente, do pleno emprego e da superação das desigualdades regionais.

Do disposto no art. 421 do novo Código Civil, à luz do artigo 170 da Constituição Federal, verifica-se que o contrato não pode mais ser analisado metafisicamente, em si mesmo, isolando o negócio e a relação jurídica com seus sujeitos partícipes. Ele deve ser estudado como um fenômeno que repercute socialmente, fora do negócio e dos sujeitos que lhe dão origem, e que passa a ser limitado pela sua função social. $O$ direito posto revitaliza o princípio da relatividade dos contratos, segundo o qual o contrato não pode gerar obrigações ou ônus para terceiros, alheios à relação contratual. Por força do princípio da relatividade e da boa-fé objetiva, depreende-se que terceiros não podem ser afetados negativamente, sob pena de nulidade do contrato (parágrafo único do art. 2.035 do novo Código Civil). E nessa concepção de "terceiros" encontram-se os interesses individuais, públicos, coletivos ou difusos.

Assim, a função social do contrato tem outro referencial, conforme corretamente identificado nos Enunciados n. 21 e 23 do Conselho da Justiça Federal. O princípio da relatividade do contrato em relação a terceiros passa a conferir a coloração predominante da função social do contrato, determinando a mitigação do princípio da autonomia da vontade, quando presentes interesses metaindividuais ou interesse individual relativo à dignidade da pessoa humana.

Para evitar-se a grave consequência da nulidade do contrato (art. 2.035, parágrafo único, do novo Código Civil), nas hipóteses de 
externalidades que afetem o meio ambiente, por exemplo, cumpre às empresas contratantes promoverem a efetiva internalização dos impactos econômicos das externalidades, com a correspondente transparência da informação mediante a contabilização dos créditos e débitos ambientais, em contas específicas nas suas demonstrações contábeis, e com apuração de um resultado ambiental. Essas podem ser medidas que contribuam com o desenvolvimento sustentável, com pleno respeito à função social do contrato.

Verifica-se, portanto, que a nova concepção da função social do contrato importa em superar as pré-compreensões fundadas nos paradigmas da função civilizatória e da afirmação da autonomia da vontade. A solidariedade e a sustentabilidade que exsurgem da Constituição de 1988, e a consequente interpretação do novo Código Civil - e do que consta do PL n. 1.572/2011 -, calcadas nesses valores e princípios preponderantes, estabelecem uma nova compreensão, que, na dialeticidade da evolução dos sistemas, será submetido à crítica pelas gerações futuras.

\section{Referências}

ANDRADE, F. S. de. Da codificação: crônica de um conceito. Porto Alegre: Editora do Advogado, 1997.

BRASIL. Presidência da República. Lei n. 6.404, de 15 de dezembro de 1976. Dispõe sobre as Sociedades por Ações. Diário Oficial [da] República Federativa do Brasil, Poder Legislativo, Brasília, DF, 15 dez. 1976. Disponível em:〈htt http://www.planalto.gov.br/ccivil_03/leis/L6404consol.htm〉. Acesso em: 23 dez. 2011.

BRASIL. Presidência da República. Lei n. 10.101, de 19 de dezembro de 2000. Dispõe sobre a participação dos trabalhadores nos lucros ou resultados da empresa e dá outras providências. Diário Oficial [da] República Federativa do Brasil, Poder Legislativo, Brasília, DF, 19 dez. 2000. Disponível em: <http:// www.planalto.gov.br/ccivil_03/leis/110101.htm>. Acesso em: 23 dez. 2011. 
BRASIL. Presidência da República. Lei n. 10.101, de 19 de dezembro de 2000. Dispõe sobre a participação dos trabalhadores nos lucros ou resultados da empresa e dá outras providências. Diário Oficial [da] República Federativa do Brasil, Poder Legislativo, Brasília, DF, 19 dez. 2000. Disponível em: <http:// www.planalto.gov.br/ccivil_03/leis/110101.htm>. Acesso em: 23 dez. 2011.

BRASIL. Presidência da República. Lei n. 10.406, de 10 de janeiro de 2002. Institui o Código Civil. Diário Oficial [da] República Federativa do Brasil, Poder Legislativo, Brasília, DF, 10 jan. 2002. Disponível em: <http://www.planalto.gov.br/ccivil_03/leis/2002/L10406.htm\#art2045>. Acesso em: 23 dez. 2011.

BRASIL. Câmara dos Deputados. Projeto de Lei n. 1572, de 2011. Institui o Código Comercial. Brasília, DF, 2001. Disponível em: <http://www.camara.gov. $\mathrm{br} /$ proposicoesWeb/fichadetramitacao?idProposicao=508884>. Acesso em: 23 dez. 2011.

COELHO, F. U. Curso de direito civil. 2. ed. revisada. São Paulo: Saraiva, 2007. v. 3.

CONSELHO DA JUSTIÇA FEDERAL. Jornada de direito civil: enunciados aprovados de ns. 1 a 137. Brasília. 2002. Disponível em: <http://www.jf.jus.br/ cjf/cej-publ/jornadas-de-direito-civil-enunciados-aprovados $>$. Acesso em: 10 ago. 2011.

FIDA, O.; CARDOSO, E. F. Contratos: teoria, prática, jurisprudência. 4. ed. São Paulo: LEUD, 1987.

FREITAS, J. Sustentabilidade: direito ao futuro. Belo Horizonte: Fórum, 2011.

HIRONAKA, G. M. F. N. A função social do contrato. Revista de Direito Civil, v. 45 , p. $141-152,1988$.

INSTITUTO BRASILEIRO DE ALTOS ESTUDOS DE DIREITO PÚBLICO. Sustentabilidade: entenda o que é a "economia verde". 2012. Disponível em: <http://www.altosestudos.com.br/?p=49117>. Acesso em: 6 maio 2011.

Rev. Direito Econ. Socioambiental, Curitiba, v. 3, n. 2, p. 335-353, jul./dez. 2012 
LICENCIAMENTO AMBIENTAL em Mato Grosso do Sul: informações sobre meio ambiente, licenciamento ambiental, tecnologias, gestão e controle ambiental. Disponível em: <http://www.licenciamentoambiental.eng.br/conceito-de-ex ternalidades/\#ixzz1u90uA1j1>. Acesso em: 6 maio 2011.

LIMA, D. V. de; VIEGAS, W. Tratamento contábil e evidenciação das externalidades ecológicas. Revista Contabilidade - Finanças - USP, n. 30, p. 46-53, 2002. PEREIRA, C. M. S. Instituições de direito civil. 8. ed. Rio de Janeiro: Forense, 1990. v. 3.

REMÉDIO Jr., J. Â. O princípio de socialidade e direitos metaindividuais: responsabilidade social. Revista de Direito Econômico e Socioambiental, v. 2, n. 2, p. 307-337, 2011.

SANTOS, J. M. C. Repertório enciclopédico do direito brasileiro. Rio de Janeiro: Borsoi, [1947?].

SILVA, L. R. F. . A função social do contrato no novo código civil e sua conexão com a solidariedade social. In: SARLET, I. W. (Org.). O novo código civil e a Constituição. 2. ed. Porto Alegre: do Advogado, 2006. p. 132-158.

WEYDMANN, C. L. Externalidades e mudanças da regulamentação ambiental para a suinocultura norte-americana: é possível no caso brasileiro? Revista de Economia e Sociologia Rural, v. 43, n. 2, p. 287-305, 2005.

Recebido: 16/08/2011

Received: 08/16/2011

Aprovado: 12/07/2012

Approved: 07/12/2012 